\title{
PELATIHAN PEMBUATAN ALAT PERMAINAN EDUKATIF (APE) PLAYDOUGH SEBAGAI SUMBER BELAJAR
}

\author{
Sumarni Sahjat ${ }^{1}$, Farida Samad $^{2}$ \\ faridasamad81@gmail.com ${ }^{1}$, sumarni_sahjat@yahoo.com² \\ ${ }^{1)}$ 2) Dosen FKIP Universitas Khairun
}

\begin{abstract}
Abstrak
Minimnya kemampuan, kreativitas dan pengalaman guru PAUD dalam memanfaatkan alat dan bahan yang tersedia walaupun secara sederhana dalam pembelajaran di kelas merupakan salah satu alasan diadakan kegiatan Program Pengabdian Masyarakat (PPM) tentang Alat Permainan Edukatif (APE) yakni playdough di gugus PAUD Kota Ternate khususnya di gugus PAUD Ternate Tengah. Adapun tujuan kegiatan PPM ini adalah untuk memberikan pengetahuan/pemahaman tentang APE playdough kepada guru-guru PAUD di gugus Ternate Tengah untuk meningkatkan kemampuan motorik halus, memberikan keterampilan kepada guru PAUD tentang APE playdough sebagai salah sumber belajar di lingkungan sekolah. APE merupakan bagian yang tidak terpisahkan dalam pembelajaran anak di TK karena alat permainan tersebut akan menunjang kegiatan pembelajaran anak secara efektif dan menyenangkan serta mengembangkan berbagai potensi yang dimiliki anak secara optimal. Dalam pelaksanaan kegiatan pengabdian ini guru PAUD gugus Ternate Tengah diberikan pelatihan pembuatan APE playdough berupa tanya jawab, demonstrasi ,diskusi dan evaluasi kegiatan. Luaran yang dicapai yaitu meningkatkan pengetahuan, kemampuan, pengalaman dan kreatifitas guru-guru PAUD se-gugus Kota Ternate dalam memanfaatkan playdough sederhana menjadi alat permainan edukatif (APE), terjalinnya kerjasama guru-guru PAUD terkait dan institusi Universitas dalam upaya peningkatan kualitas pembelajaran bagi anak usia dini, publikasi jurnal dan publikasi media massa.
\end{abstract}

Keywords: playdough, APE, sumber belajar

\section{PENDAHULUAN}

Kota Ternate terdiri dari beberapa PAUD yang tersebar di gugus Ternate Utara, gugus Ternate Tengah dan gugus Ternate Selatan dengan jumlah PAUD yang tersebar mencapai 120an PAUD pada beberapa tahun terakhir. PAUD diyakini menjadi dasar bagi penyiapan sumber daya manusia yang berkualitas di masa mendatang. Oleh karena itu, layanan PAUD harus dirancang dengan seksama dengan memperlihatkan perkembangan anak, perubahan ilmu pengetahuan dan teknologi serta budaya yang berkembang. Produk utama dalam Pelaksanaan Program Pengabdian Masyarakat (PPM) ini adalah tentang Alat Permainan Edukatif (APE). APE merupakan bagian yang tidak terpisahkan dalam 
pembelajaran anak di TK. Ketersediaan alat permainan tersebut sangat menunjang terselenggaranya pembelajaran anak secara efektif dan menyenangkan sehingga anak-anak dapat mengembangkan berbagai potensi yang dimilikinya secara optimal. Pelaksanaan program pengabdian ini selanjutnya akan diberikan pelatihan yakni pelatihan pembuatan alat permainan edukatif playdough sebagai sumber belajar. Adapun pelatihan yang nantinya akan diajarkan adalah bagaimana tepung terigu, minyak, pewarna serta bagaimana mengolah dan membentuk berbagai playdough ini untuk siap dan digunakan sebagai sumber belajar bagi anak-anak PAUD segugus Kota Ternate. Adapun yang menjadi latar belakang permasalahan diadakannnya pengabdian pada masyarakat antara lain: kurangnya pengetahuan, kemampuan, pengalaman dan kreatifitas para guru PAUD segugus Kota Ternate ini dalam memanfaatkan alat dan bahan sederhana menjadi alat permainan edukatif (APE) yang sederhana untuk anak usia dini. Untuk mengatasi permasalahan tersebut perlunya para guru-guru PAUD diberikan pelatihan berupa Tanya jawab, demonstrasi dan diskusi tentang playdough sebagai sumber belajar agar meningkatkan pengetahuannya dalam membentuk playdough menjadi sumber belajar sederhana yang memiliki nilai edukatif. Setelah permasalahan ini terjawab maka diharapkan dengan pengalaman tersebut bisa mengembangkan beberapa alat permainan edukatif lainnya yang bisa bernilai edukatif tinggi.

\section{METODE}

Metode pelaksanaan pelatihan Alat Permainan Edukatif (APE) playdough sebagai sumber belajar di guru-guru PAUD segugus Ternate Utara, gugus Ternate Tengah dan gugus Ternate Selatan seperti di bawah ini: 


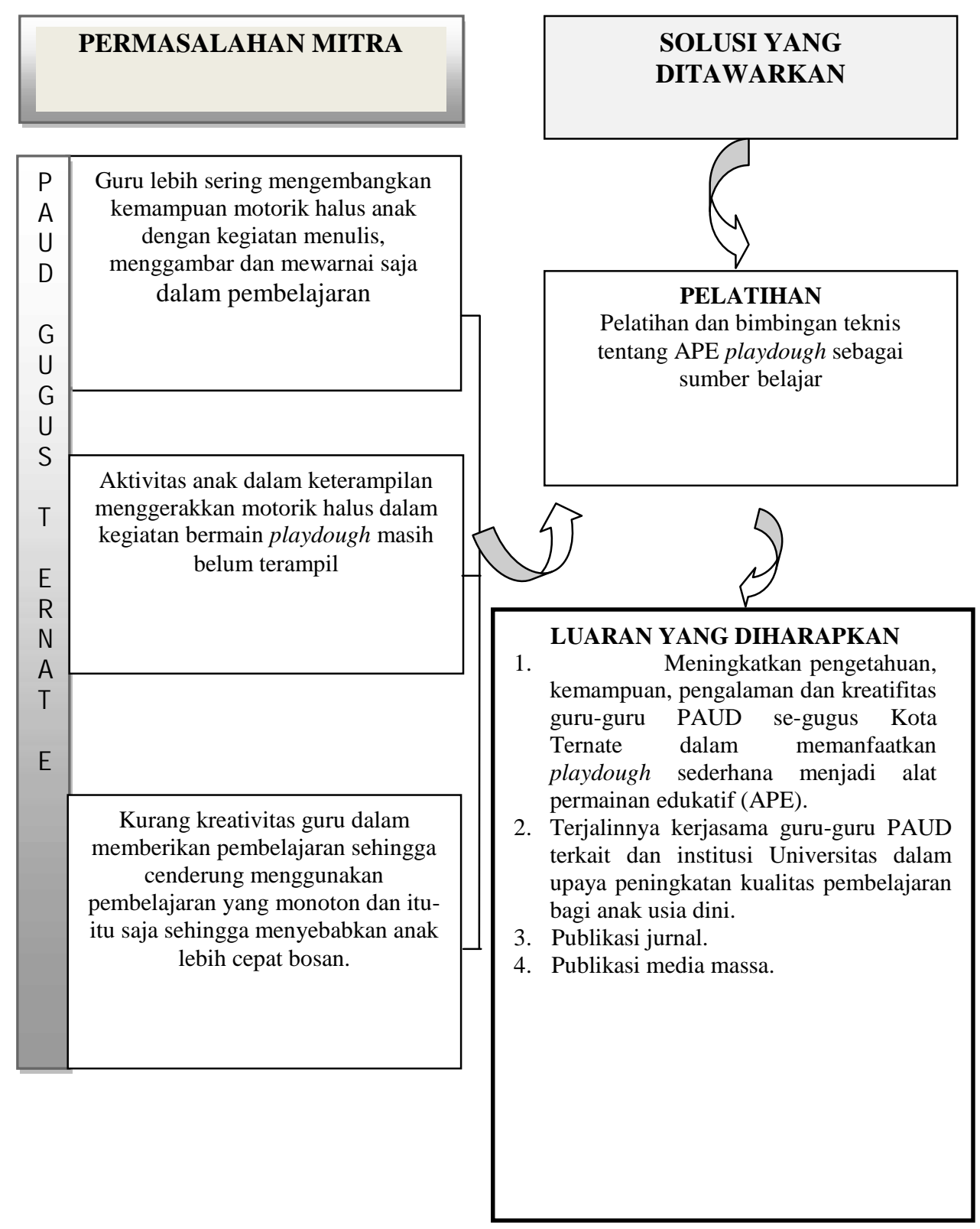

PEMBAHASAN

Hasil pelaksanaan kegiatan pengabdian kepada masyarakat (PPM) dilaksanakan melalui pemberian materi dan pelatihan kepada para guru PAUD se- 
kota Ternate yang berada di 3 gugus yakni gugus Ternate Utara, gugus Ternate Tengah dan gugus Ternate Selatan tentang bagaimana proses membuat sebuah alat permainan edukatif (APE) berbahan playdough sebagai sumber belajar di kelas. Kegiatan ini dilaksanakan secara baik dan lancar dengan metode pelaksanaan pelatihan dilaksanakan melalui metode tatap muka dengan metode ceramah dan demonstrasi, dilanjutkan dengan pelatihan/praktek langsung untuk membuat alat permainan edukatif ( APE) tersebut .

Kegiatan ini dilaksanakan selama dua hari yaitu 17 Juli 2017 dan 18 Juli 2017 pada pukul 10.00-13.00 WIT. Pelaksanaan kegiatan dilaksanakan di Laboratorium PAUD FKIP Kampus I Akehuda di Jalan Bandara Babullah Kota Ternate. Pelaksanaan kegiatan pelatihan pembuatan alat permainan edukatif (APE) playdough ini diikuti oleh guru PAUD yang berjumlah 25 orang dengan pokok bahasan dan pelatihan meliputi:

1. Pentingnya APE sebagai sumber belajar PAUD

2. Pelatihan teknis membuat Alat Permainan Edukatif play dough

Beberapa kegiatan diatas dilaksanakan selama dua hari, dengan pembagian menjadi dua kelompok kegiatan, yaitu di hari pertama dilakukan praktek langsung membuat produk APE playdough.

Para guru PAUD se-gugus Kota Ternate Tengah sangat bersemangat mengikuti kegiatan ini. Disamping beberapa bentuk dan pola APE yang diajarkan sangat mudah juga dihasilkan sangat unik, tentu saja kegiatan ini mengundang rasa tertarik para guru PAUD tentang bagaimana membentuk pola atau gambar playdough agar bisa digunakan sebagai sumber belajar di kelas. Kegiatan pelatihan di hari pertama ini difokuskan agar para guru PAUD bisa membuat bentuk playdough ini hingga siap untuk gunakan di kegiatan pembelajaran. Mulai dari pencampuran bahan sampai pada pengolahan bahan hingga menghasilkan bentuk APE yang unik seperti model flower (bunga), pelangi, angka dan lain-lain. dibawah ini illustrasi hasil pembuatan produk APE playdough pada gambar 1 berikut. 


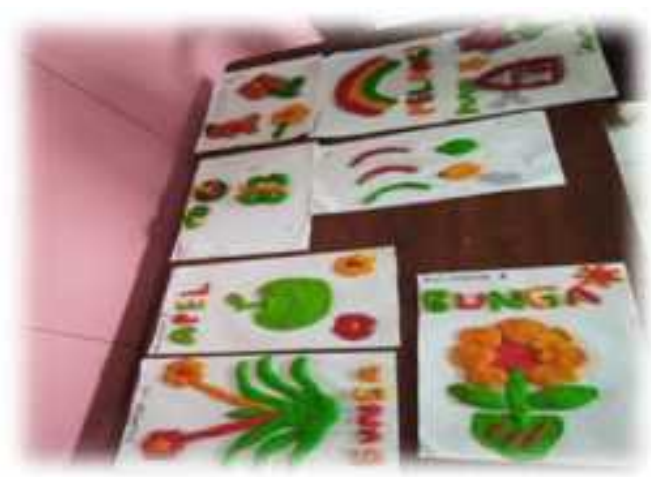

Gambar 1. Berbagai macam bentuk bunga

Selain dari kardus alami, produk APE juga bisa dibuat dengan mengkombinasikan kertas warna ataupun menggunakan cat, produk yang dihasilkan juga lebih unik dan berkesan hidup, seperti pada gambar 2 berikut.

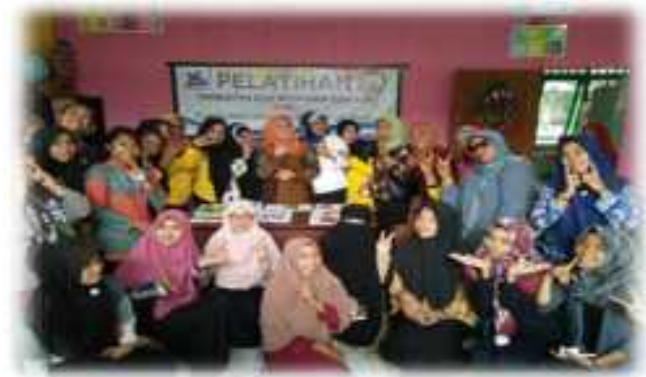

Gambar 2. Kegiatan pelatihan bersama guru PAUD se-gugus Kota Ternate

Selain kombinasi warna, juga bisa dilakukan kombinasi dengan bahan lainnya sehingga dapat menghasilkan bentuk yang lebih unik karena tingkat kreatifitas yang tinggi dan mampu menciptakan bentuk-bentuk yang lebih banyak.

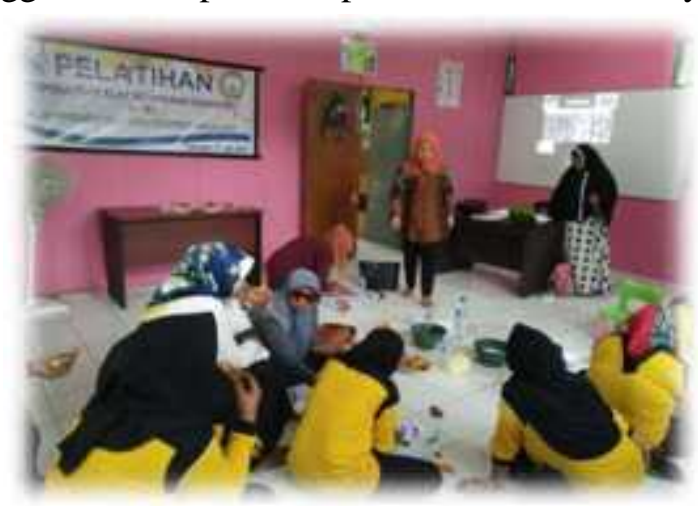

Gambar 3. Proses pembuatan playdough di lab PAUD 
Setelah praktek pembuatan APE playdough selesai, tepatnya pada tanggal 18 Juli 2017 berlangsung, maka selanjutnya dilakukan evaluasi hasil kegiatan.

\section{Evaluasi Kegiatan}

Kegiatan evaluasi dilaksanakan sebagai monitoring atas hasil yang dicapai atas beberapa kegiatan sebelumnya apakah terdapat kendala yang dihadapi para guru-guru PAUD se-Kota Ternate selama mengikuti pelatihan dan dalam melaksanakan proses pencampuran hingga pengolahan bahan playdough. Kegiatan evaluasi ini sangat bermanfaat untuk mengukur kemampuan masing-masing peserta pelatihan dalam menyerap sehingga mempermudah proses pendampingan pada tahap berikutnya.

Hasil penilaian menunjukkan ilmu yang telah diserap oleh masing-masing guru PAUD se-Kota Ternate secara rinci dapat dilihat pada grafik 1 berikut.

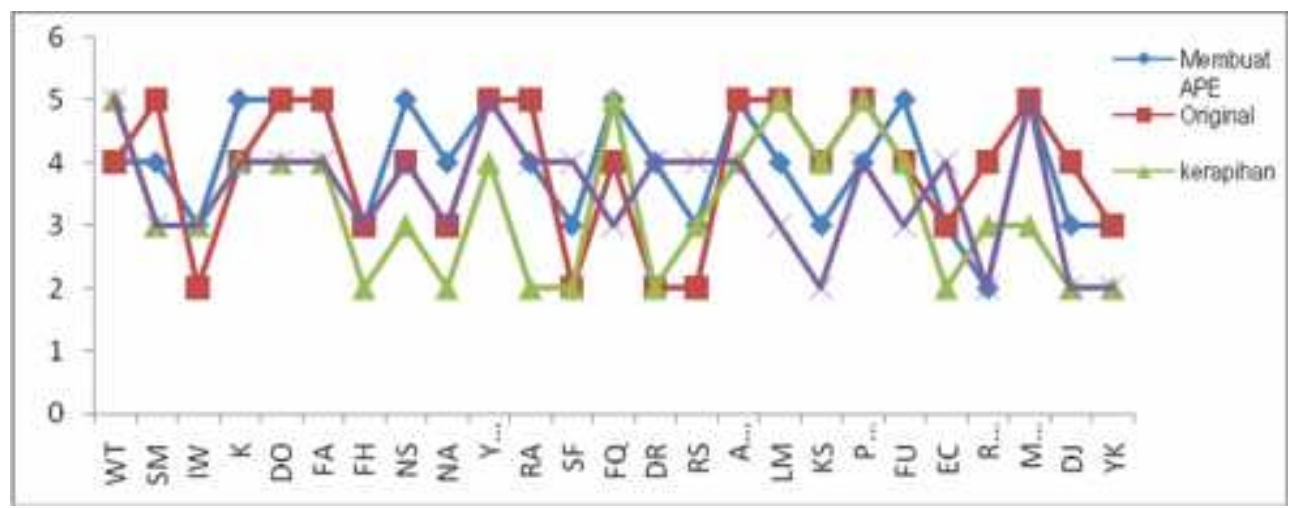

Grafik 1. Profil Evaluasi Tingkat Kemampuan Guru PAUD se-Gugus Kota Ternate

Hasil diatas sebagai gambaran seberapa jauh para guru-guru PAUD se-Kota Ternate yang telah diberikan pelatihan bisa menyerap ilmu yang diberikan dan apakah mampu untuk diterapkan. Kedepannya diharapkan melalui program pengabdian yang dilaksanakan ini banyak memberikan manfaat bagi guru-guru PAUD lainnya di Kota/Kabupaten lainnya.

\section{SIMPULAN}

Program Pengabdian bagi Masyarakat (PPM) mempunya manfaat khususnya bagi guru-guru PAUD di se-gugus Kota Ternate dalam upaya peningkatan pengetahuan, kemampuan, kreativitas dan luaran yang dicapai dari kegiatan pengabdian ini adalah : 
1) Meningkatnya pengetahuan dan kemampuan guru PAUD tentang APE playdough

2) Terjalinnya kerjasama guru-guru PAUD terkait dan institusi Universitas dalam upaya peningkatan kualitas pembelajaran bagi anak usia dini.

3) Publikasi jurnal

4) Publikasi media massa

\section{DAFTAR PUSTAKA}

Depdiknas. 2007. Pedoman Pembelajaran Bidang Pengembangan Fisik Motorik di Taman Kanak-Kanak. Jakarta: Direktorat Pembinaan Taman Kanak-Kanak dan Sekolah Dasar

Hussein,Magda dkk. 2007. Bidang Motorik Halus.Jakarta: Departemen Pendidikan Nasional.Direktorat jenderal Pendidikan Luar Sekolah dan Pemuda.Direktorat Pendidikan Anak Dini Usia (PADU)

Noorlaila,Iva. 2010. Panduan Lengkap Mengajar PAUD. Kreatif Mendidik dan Bermain Bersama Anak.Yogyakarta: Pinus Book.

Nur,Jatmika Yusep. 2012. Ragam Aktivitas Harian untuk Taman Kanak-Kanak. Yogyakarta: Diva Press

Rahayu, Liswidyawati. 2010. 20 Fun Activities For Todller. Surakarta: Indiparent.

Sujiono, Bambang. 2007. Metode Pengembangan Fisik. Jakarta: Universitas Terbuka

Saputra M, Yudha dan Rudyanto. 2005. Pembelajaran Kooperatif untuk Meningkatkan Keterampilan Anak TK. Jakarta: Direktorat Pembinaan Pendidikan Tenaga Kependidikan Dan Ketenagaan Perguruan Tinggi Departemen Pendidikan Nasional.

Sujiono, Yuliani Nurani. 2009. Konsep Dasar Pendidikan Anak Usia Dini.Jakarta: PT Indeks.

Sujiono, Bambang dkk. 2007. Metode Pengembangan Fisik. Jakarta: Penerbit Universitas Terbuka.

Sumanto. 2005. Pengembangan Kreativitas Seni Rupa Anak TK. Jakarta: Departemen Pendidikan Nasional Direktorat Jenderal Pendidikan Tinggi Direktorat Pembinaan Pendidikan Tenaga Kependidikan Dan Ketenagaan Perguruan Tinggi.

Sumantri. 2005. Model Pengembangan Keterampilan Motorik Anak Usia Dini.Jakarta: Departemen Pendidikan Nasional Direktorat Jenderal Pendidikan Tinggi Direktorat Pembinaan Pendidikan Tenaga Kependidikan Dan Ketenagaan Perguruan Tinggi.

Suyanto, Slamet. 2005. Dasar - Dasar Pendidikan Anak Usia Dini.Yogyakarta:

Seefeldt, Carol dan Barbara A. Wasik. 2006.Pendidikan Anak Usia Dini (Terjemahan)Jakarta:PT Indeks Indonesia 
Yamin,Martinis dan Sabri,Sanan. 2010. Panduan Pendidikan Anak Usia Dini. Jakarta: GP Press.

Hartati, Sri. 2009 : Media Pembelajaran AUD. Padang. UNP PRESS Penilaian, Pembuatan dan Penggunaan Sarana (Alat Peraga) di Taman Kanak-kanak . Jakarta: 